BLS 33, No 1 2007. DOI: http://dx.doi.org/10.3765/bls.v33i1.3532

(published by the Berkeley Linguistics Society and the Linguistic Society of America)

\title{
Dative External Possessor Constructions in Sidaama
}

\author{
KAZUHIRO KAWACHI \\ University at Buffalo, State University of New York
}

\section{Introduction ${ }^{1}$}

This study shows that the existence of the dative external possessor construction (Dative EPC) in Sidaama, a Cushitic language of Ethiopia, challenges König \& Haspelmath's (1998; Haspelmath 1999) hypothesis that the Dative EPC is limited to a central and southern area of Europe and is found nowhere else in the world. It also questions the applicability of portions of Haspelmath's (1999) analysis of the polysemy of a dative marker on a semantic map, which is based on the dative markers in a small number of European languages, to the Sidaama dative.

Section 2 reviews crosslinguistic studies of the Dative EPC by König \& Haspelmath (1998) and Haspelmath (1999). Section 3 describes the Sidaama Dative EPC. Section 4 looks into the Sidaama dative in general, and demonstrates that unlike some European datives, which occupy a portion of Haspelmath's semantic map of a dative marker, it covers almost all the senses on it. Section 5 examines the relations between the Dative EPC and two other types of dative constructions, the benefactive and judicantis constructions, in this language, and shows how the Dative EPC is related not only to the benefactive construction, as indicated on Haspelmath's semantic map, but also to the judicantis construction. Section 6 concludes the paper.

\section{Previous Studies}

An external possessor construction (EPC) is a construction where the possessor is expressed in a constituent external to the possessum NP (e.g., Chappell \& McGregor 1996, Payne \& Barshi 1999), unlike in an internal possessor construction (IPC), where the possessor is expressed as a dependent of or an affix on the possessum noun. In an EPC, the possessive relation between the two entities is

\footnotetext{
${ }^{1}$ I would like to convey my profound thanks to my Sidaama native speaker consultant, Dr. Abebayehu Aemero Tekleselassie (from Daayie Village in the Baansa district of the Sidaama zone of Ethiopia), for the consultation sessions that we have had over the years. I am also sincerely grateful to Dr. Matthew S. Dryer, Dr. Leonard Talmy, and Dr. Jürgen Bohnemeyer for their advice and comments on a study on which portions of the present paper are based (Kawachi 2007).
} 


\section{Kazuhiro Kawachi}

neither morphologically specified nor lexically expressed, but is inferred from the use of the construction. There are various types of EPCs where the possessor NP and the possessum NP exhibit different combinations of grammatical relations. The Dative EPC is a type of EPC where the possessor NP is in the dative case.

König \& Haspelmath (1998; Haspelmath 1999) investigated about thirty languages in Europe and found that there are four syntactic patterns of the Dative EPC in those languages, which are shown in (1) (adapted from Haspelmath 1999:110).
(1) (a) Subj
V DAT(possessor) Obj(possessum)
(b) Subj(possessum) V DAT(possessor)
(c) Subj
$\mathrm{V}$ DAT(possessor)
(d) Subj
$\mathrm{V}$ DAT(possessor) Obj
$\mathrm{PP}($ possessum $)$
$\mathrm{PP}($ possessum $)$

According to them, the Dative EPC has to fulfill a strict mental affectedness condition, and can be used only when the possessor is mentally affected by the event. They hypothesize that the mental affectedness condition that has to be met for the use of (not only the Dative EPC but) an EPC in general can be characterized to some extent in terms of the four implicational hierarchies in (2): if an EPC can be used at one point on each of the hierarchies, it can also be used at any higher position on it. An EPC is favored when an item higher on the hierarchy is involved, and there is often a cut-off point below which an EPC cannot be used.

(2) (a) The Animacy Hierarchy (possessor): 1st/2nd p. pronoun $\subset 3 \mathrm{rd}$ p. pronoun $\subset$ proper name $\subset$ other animate $\subset *$ inanimate

(b) The Situation Hierarchy (predicate): patient-affecting $\subset$ dynamic nonaffecting $\subset *$ stative

(c) The Inalienability Hierarchy (possessum): body part $\subset$ garment $\subset$ other contextually unique item

(d) The Syntactic Relations Hierarchy (possessum): PP $\subset$ direct object $\subset$ unaccusative subject $\subset$ unergative subject $\subset *$ transitive subject

König \& Haspelmath also found that the existence of the Dative EPC is an areal feature of central and southern European languages, which may or may not be Indo-European languages. They also claim that even though there are different types of EPCs attested in various parts of the world, there is no language outside Europe that has the Dative EPC. The last point is disproved in the next section.

Haspelmath (1999) analyzes various senses of dative markers in different languages on a semantic map shown in Figure 1, where he proposes the possible senses of the dative are arranged based on their conceptual similarity, though he does not provide any explanation of exactly how the senses are related. 


\section{Dative External Possessor Construction in Sidaama}

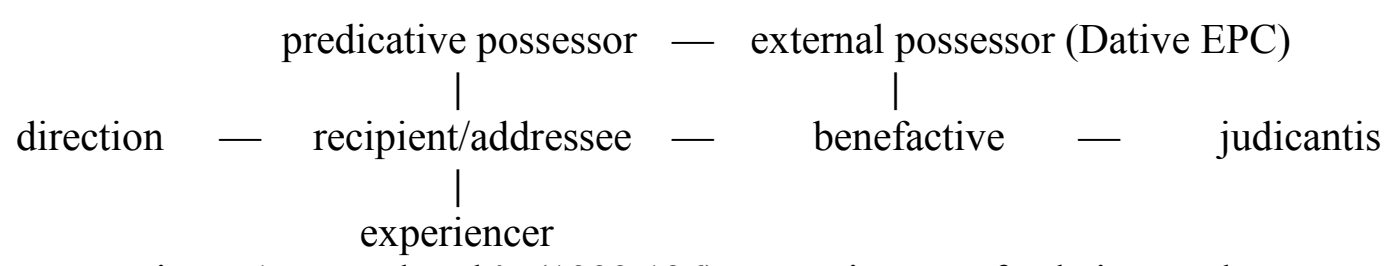

Figure 1: Haspelmath's (1999:126) semantic map of a dative marker

Using this map, Haspelmath makes the following claims. First, the dative marker in any language occupies a contiguous area on this map. Second, diachronically, the dative marker in any language develops from the left on the map gradually to the right, and as it acquires new senses on the right, it loses senses on the left. A dative marker cannot be used for too many of the senses on the map, and in order for the Dative EPC to exist in a language, its dative marker has to be sufficiently grammaticalized and desemanticized to the extent that it does not express direction. However, as he admits, this map is based on only a few European languages, and needs to be tested against many other languages. In Section 4, it is shown that the Sidaama dative marker works slightly differently from Haspelmath's hypotheses.

\section{Dative EPC in Sidaama}

Sidaama is a Highland East Cushitic language spoken in South Central Ethiopia (Kawachi 2004, 2006a, 2006b, 2007). The word order is predominantly SOV, and the case-marking system is accusative. ${ }^{2}$

For the dative case, Sidaama uses a suffix, which has three allomorphs, -te, $h o$, and -ra (glossed as DAT.F, DAT.M, and DAT, respectively) - -te and -ho are used for feminine and masculine common nouns that are accompanied by neither a dependent nor the possessive pronominal suffix, respectively, and $-r a$ attaches to the genitive stems of all the other types of nominals. ${ }^{3}$

The Dative EPC in Sidaama basically covers all the syntactic patterns of the European Dative EPC in (1), though this language uses not adpositions but suffixes. ${ }^{4}$ The syntactic patterns comparable to the European patterns, (1a), (1b), (1c), and (1d), are exemplified by (3) and (4), (5) and (6), (7) and (8), and (9) and (10), respectively. ${ }^{5}$ Note that as long as the verb comes finally, the word order is flexible, though the possessor NP usually precedes the possessum NP.

\footnotetext{
2 The accusative case is indicated with high pitch on the final vowel segment of the stem.

3 The nominative and genitive suffixes, as well as the dative and locative suffixes (which have the same set of allomorphs), take different forms, depending on the gender and the type of the nominal (in the case of a common noun, also whether it is accompanied by a dependent or the possessive pronominal suffix), though every detail is not reflected in the gloss for each allomorph of the suffixes. See Kawachi (2007) for complete descriptions.

${ }^{4}$ There are also a few other patterns. See Kawachi (2007) for details.

${ }^{5}$ Abbreviations. EP: epenthesis, NPC: noun-phrase clitic, PERF: present perfect.
} 
- Pattern (a): Subj DAT(possessor) Obj(possessum) trans.V

(3) bule damboow-i-ra

Bule(NOM.F) Damboowa-GEN.M-DAT

(a)č'ulunk'á/(b)rodoó/(c)hakk'iččó mur-t-ino.

nail(ACC)/sibling(ACC)/tree(ACC) cut-3SG.F-PERF.3

'Bule cut Damboowa's (a)nails/(b)sibling/(c)tree.' (lit., 'Bule cut the (a)nails/(b)sibling/(c)tree to Damboowa.')

bule hakk'iččo-te siná mur-t-ino.

Bule(NOM.F) tree-DAT.F branch(ACC) cut-3SG.F-PERF.3

'Bule cut the branches of the tree.' (lit., 'Bule cut the branches to the tree.')

- Pattern (b): Subj(possessum) DAT(possessor) intrans.V

(5)

$$
\text { damboow-i-ra (a)č'ulunk'a/(b)rodoo/(c)hakk'iččo }
$$

Damboowa-GEN.M-DAT nail(NOM.F)/sibling(NOM.F)/tree(NOM.F) seed-d-ino.

become.long-3SG.F-PERF.3

'Damboowa's (a)nails became long (and are long now)/(b)sister became tall (and is tall now)/(c)tree became tall (and is tall now).' (lit., 'To Damboowa, the (a)nails became long/(b)sister became tall/(c)tree became tall.' $)^{6}$

(6)
hakk'iččo-te sin-u seed-ø-ino.

tree-DAT.F branch-NOM.M become.long-3SG.M-PERF.3

'The branches of the tree became long (and are long now).' (lit., 'To the tree, the branches became long.')

- Pattern (c): Subj DAT(possessor) (possessum)-suffix intrans.V

(7) ise isi-ra

3SG.F.NOM 3SG.M.GEN-DAT

(a)giwooda-ho/(b)rodoo-te/(c)barč'uma-ho ofol-t-ino.

lap-LOC.M/sibling-LOC.F/stool-LOC.M sit-3SG.F-PERF.3

'She sat on his (a)laps/(b)sister/(c)stool (and is sitting there now).' (lit., 'She sat at the (a)lap/(b)sister/(c)stool to him.')

(8) ise
hakk'iččo-te sinčo-ho
ofol-t-ino.
3SG.F.NOM tree-DAT.F branch-LOC.M sit-3SG.F-PERF.3

'She sat on the branch of the tree (and is sitting there now).' (lit., 'She sat at the branch to the tree.')

\footnotetext{
${ }^{6}$ As suggested in the English glosses for some of the examples, Sidaama uses the perfect forms of state-change verbs to express non-inherent and temporary states as conditions resulting from the state changes by the state-change verbs (Kawachi 2006b, 2007). Adjectives and nouns are restricted to inherent properties.
} 
- Pattern (d): Subj DAT(possessor) Obj (possessum)-suffix trans.V

$\begin{array}{llll}\text { (9) } & \text { ise } & \text { buná } & \text { isi-ra } \\ & \text { 3SG.F.NOM } & \text { coffee(ACC) } & \text { 3SG.M.GEN-DAT }\end{array}$

(a)giwooda-ho/(b)k'aakk'o-te/(c)barč'uma-ho dun-t-ino. lap-LOC.M/baby-LOC.F/stool-LOC.M spill-3SG.F-PERF.3

'She spilled coffee on his (a)laps/(b)baby girl/(c)stool.' (lit., 'She spilled coffee at the (a)laps/(b)baby girl/(c)stool to him.')

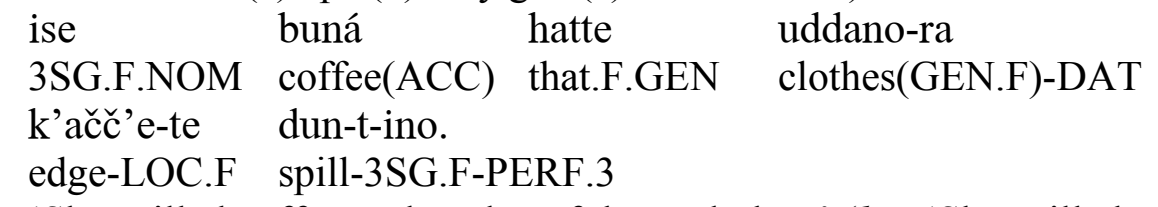

'She spilled coffee at the edge of those clothes.' (lit., 'She spilled coffee at the edge to those clothes.')

The Sidaama Dative EPC has characteristics such as the following. First, any instance of the Dative EPC has an IPC counterpart (or IPC counterparts), where the possessor is expressed with a genitive NP, as in (6'), or the possessive pronominal suffix, as in (7a').

hakk'iččo-te sin-i seed-ø-ino. tree-GEN.F branch-NOM.M become.long-3SG.M-PERF.3

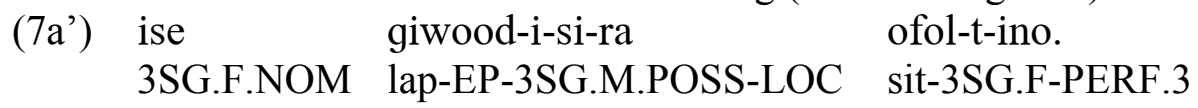

'She sat on his laps (and is sitting there now).'

Second, in a Dative EPC sentence, an animate possessor can be additionally indicated with the possessive pronominal suffix on the possessum noun; in other words, an IPC can be optionally formed within the dative EPC, as in (3').

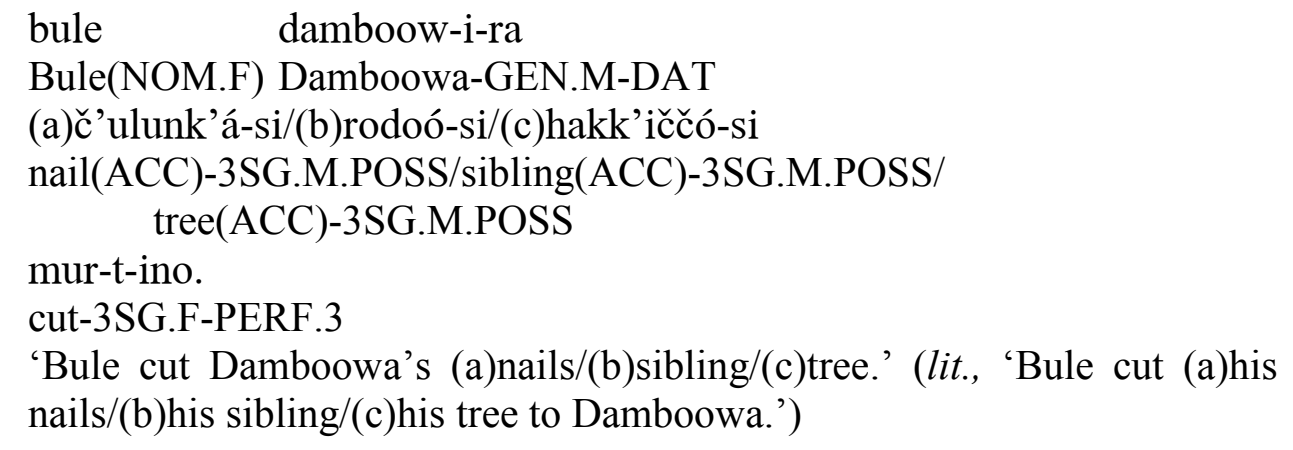

Third, in a Dative EPC sentence, an animate possessor can be additionally indicated with the pronominal object suffix on the verb, as in (5'). Instead of being expressed by a full dative NP, an animate possessor can be indicated only by the pronominal object suffix on the verb. For example, even without damboow-i-ra, 


\section{Kazuhiro Kawachi}

the sentences in $\left(5^{\prime}\right)$ are grammatical ones, which mean 'His (a)nails became long (are long)/(b)sister became tall (is tall)/(c)tree became tall (is tall)'.

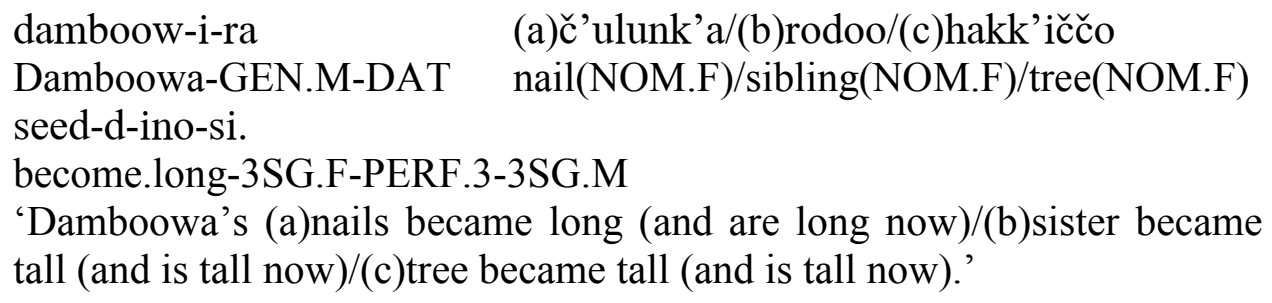

The second and third characteristics of the Dative EPC yield a wide variety of subtypes.

Another property of the Dative EPC in Sidaama is that it usually conveys a beneficial or adversative experience of the possessor from the speaker's point of view, rather than simply expressing the possessive relationship between the two entities. This point is returned to shortly.

If the Sidaama Dative EPC is placed on König \& Haspelmath's hierarchies in (2), it turns out that it is less constrained than its European counterparts. First, it can be used for inanimate as well as animate possessors, as shown in (4), (6), (8), and (10), though it is only when the possessor is animate that the Dative EPC can use the possessive pronominal suffix on the possessum noun or the pronominal object suffix on the verb. Second, the Sidaama Dative EPC can use not only patient-affecting predicates, but also stative predicates. As in (11) and (12), the predicate in the Dative EPC can be an adjective.

- Pattern (b'): Subj(possessum) DAT(possessor) Adj

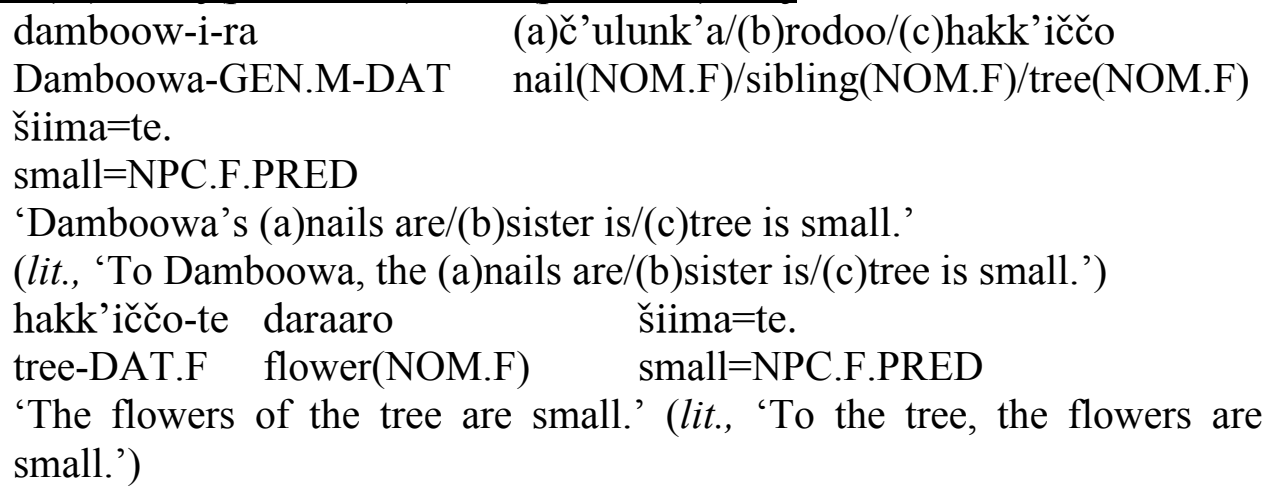

Finally, the possessum does not have to be inalienably possessed items, but can be alienably possessed items, as in (3c), (5c), (7c), (9c), and (11c). There does not seem to be any restriction on the type of possessum. However, the Sidaama Dative EPC is similar to the European ones with respect to the hierarchy in (2d); the possessum may be a direct object, an intransitive subject, the subject of an adjective predicate, or a locative NP, but can never be a transitive subject, because 


\section{Dative External Possessor Construction in Sidaama}

the possessor is normally affected by the event or state also in the Sidaama Dative EPC.

\section{Dative in Sidaama}

The Sidaama dative marker covers almost all the senses on Haspelmath's (1999) semantic map.

- Direction: The allative suffix -ra, which marks the goal of a motion, as in (13), has the same form as one of the allomorphs of the dative suffix.

\begin{tabular}{|c|c|c|c|}
\hline $\begin{array}{l}\text { ise } \\
3 \mathrm{SG} F \mathrm{NOM}\end{array}$ & $\begin{array}{l}\text { hakko } \\
\text { that M GEN }\end{array}$ & $\begin{array}{l}\text { god-i-ra } \\
\text { gave-GFN M-ALI }\end{array}$ & ha-3-ino. \\
\hline
\end{tabular}

This suffix attaches to four types of nominals that refer to locations, specifically, masculine common nouns with a dependent or the possessive pronominal suffix whose referents can be regarded as locations, masculine proper nouns for locations, locational nouns (e.g., giddo 'inside'), and demonstrative pronouns. (Other types of nominals, when referring to the goal of a motion, are used without -ra.) The allative suffix - $r a$ is used for roughly the same set of types of nominals as one of the allomorphs of the dative suffix - $r a$, which has the same form as the allative suffix. Because the two other allomorphs of the dative suffix, -ho and -te, cannot be used as the allative suffix, the dative suffix and the allative suffix are not the same morpheme. Nevertheless, they seem to be related to each other. As Haspelmath argues, the dative may have been grammaticalized to the extent that only one of its allomorphs is still used as the allative suffix, though, to my knowledge, the historical development of this suffix has not been reported in the literature.

- Recipient/addressee: Both recipients and addressees are marked with the dative case suffix, as in (14) and (15), respectively.

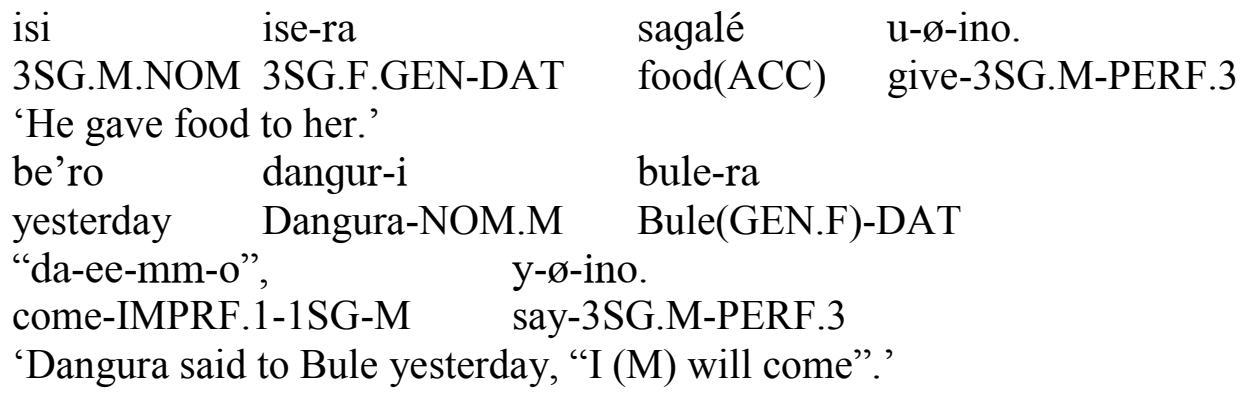

- Experiencer: Sidaama has a series of transitive verbs or causative verb forms that take an impersonal third-person singular masculine subject and a dative or accusative experiencer. A dative example is shown in (16). 


\section{Kazuhiro Kawachi}

(16)

ise-ra t'iss-ø-ino.

3SG.F.GEN-DAT cause.sickness-3SG.M-PERF.3

'She is sick.' (lit., '(Impersonal 3SG.M subject) caused sickness to her.')

- Predicative possessor: Sidaama has a predicate possession construction with an existential/locational-verb predicate, where the possessor is in the dative case and the possessum is the subject. The existential/locational verb in Sidaama is a statechange verb 'to come to exist/be located', which is always in the present perfect. In the predicate possession construction, the existential/locational verb has an invariant form no, which is a form for a third-person subject. As Haspelmath indicates on his map, this construction is related to the Dative EPC also in Sidaama. In fact, it looks like a variant of the Dative EPC of the syntactic pattern (b) (Subj(possessum) DAT(possessor) intrans.V). Examples are shown in (17) and

$$
\begin{array}{lll}
\text { isi-ra } & \min -\mathrm{u} & \text { no. } \\
\text { 3SG.M.GEN-DAT } & \text { house-NOM.M } & \text { come.to.exist.PERF.3 }
\end{array}
$$

'He has a house.' (lit., 'To him, a house came to exist.')
mine-ho
lam-u
waalč-i
no.

house-DAT.M two-NOM.M door-NOM.M come.to.exist.PERF.3

'The house has two doors.' (lit., 'To the house, two doors came to exist.')

Examples of the benefactive construction and the judicantis construction (König \& Haspelmath 1998; Haspelmath 1999; e.g., English: That is too difficult for me) are shown in (19) and (20), respectively. These two constructions are discussed in detail in the next section.

\section{- $\underline{\text { Benefactive }}$}

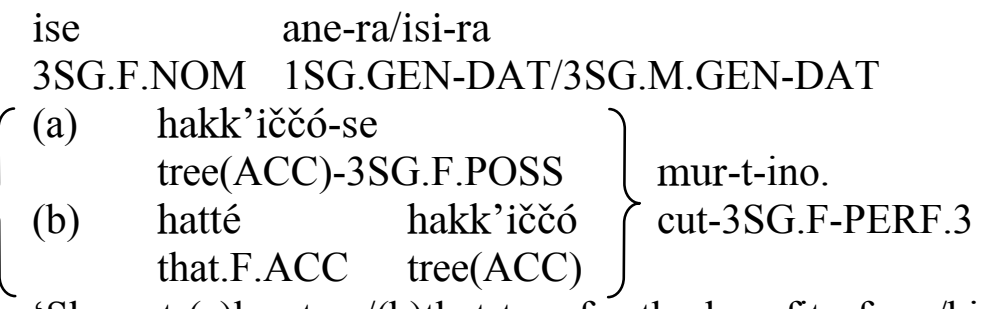

'She cut (a)her tree/(b)that tree for the benefit of me/him.' (She believed that (a)her tree/(b)that cutting her tree would be beneficial to me/him.) 
- Judicantis

$\begin{array}{ll}\text { ise-ra } & \text { damboow-i } \\ \text { 3SG.F.GEN-DAT } & \text { Damboowa-NOM.M }\end{array}$

(a)t'ur-ø-ino/(b)seeda=ho.

become.dirty-3SG.M-PERF.3/tall=NPC.M.PRED

'Damboowa (a)became dirty (and is dirty now)/(b)is tall for her.' (in her judgment)

\section{Dative EPC and Two Other Dative Constructions in Sidaama}

This section compares the Dative EPC with two other types of dative constructions, specifically the Dative EPC of the syntactic pattern (a) with the benefactive construction, and the Dative EPC of the syntactic patterns (b) and (b') with the judicantis construction, and shows the ways that the Dative EPC is related not only to the benefactive construction, as indicated on Haspelmath's (1999) map, but also to the judicantis construction.

Hereafter, the referent of the dative NP is called a 'dative entity', and the directly affected entity undergoing a state change or the entity whose state is described is called a 'patient/theme entity'. In the benefactive and judicantis constructions as well as the Dative EPC, a patient/theme entity is expressed as the direct object of a transitive verb or the subject of an intransitive-verb or adjectival predicate. Generally, in the subtypes of the Dative EPC that follow the syntactic patterns (a), (b), and (b'), the possessum NP is a patient or theme, regardless of whether it is the subject of an intransitive-verb or adjective predicate or the object of a transitive-verb predicate. In the following discussion, which limits the Dative EPC to its subtypes with the above three syntactic patterns, structural correspondences between the Dative EPC and the benefactive and judicantis constructions are presented, and then how they can be distinguished is explored.

The benefactive construction takes one of the forms in $(21)-(21 \mathrm{a})$ uses a transitive verb (e.g., (19)), and (21b) uses an intransitive verb (e.g., 'She came for the benefit of me/him.') (the order of the constituents in the benefactive construction is flexible except that the verb has to be final). It is only when the verb of the benefactive construction is transitive, as in (21a), that a patient/theme entity is relevant; the object of the transitive verb is normally a patient or theme. In the benefactive construction with an intransitive verb like (21b), the subject is usually not a patient or theme, but an agent. Thus, this construction is irrelevant and is excluded from the discussion hereafter.

$$
\begin{array}{lllll}
\text { a. } & \text { Subj } & \text { DAT(dative entity) } & \text { Obj(patient/theme) } & \text { trans.V } \\
\text { b. } & \text { Subj } & \text { DAT(dative entity) } & & \text { intrans.V }
\end{array}
$$

The benefactive construction with a transitive verb predicate in (21a) is structurally parallel to the Dative EPC with a transitive verb predicate (syntactic pattern (a) in section 3: Subj DAT(possessor) Obj(possessum) trans.V). 


\section{Kazuhiro Kawachi}

As exemplified by (20), the other type of dative construction, the judicantis construction (König \& Haspelmath 1998; Haspelmath 1999), whose predicate is an intransitive verb or an adjective, expresses a state change or state in the judgment of the dative entity, which is usually animate. It takes the forms in (22), where the order of the subject NP and the dative NP can be reversed.

$$
\begin{array}{llll}
\text { a. } & \text { Subj(patient/theme) } & \text { DAT(dative entity) } & \text { intrans.V } \\
\text { b. } & \text { Subj(patient/theme) } & \text { DAT(dative entity) } & \text { Adj }
\end{array}
$$

(22a) and (22b) are structurally the same as the Dative EPC of the syntactic patterns (b) (Subj(possessum) DAT(possessor) intrans.V) and (b') (Subj(possessum) DAT(possessor) Adj), respectively.

There are two additional respects in which the benefactive construction with a transitive verb and the judicantis construction show structural commonalities with the Dative EPC. First, just as the pronominal object suffix that refers to an animate possessor can occur on the verb in the Dative EPC that uses a verb as its predicate, the pronominal object suffix that refers to an animate dative entity can attach to the verb in the benefactive construction with a transitive verb or in the judicantis construction with an intransitive verb (e.g., instead of (19a), ise isira hakk'iččo-se mur-t-ino-si). Second, as in the Dative EPC, the dative entity in the benefactive and judicantis constructions may be indicated only by the pronominal object suffix, instead of being expressed by a full NP (e.g., instead of (20a), damboow-i t'ur-ø-ino-se).

There are mainly two respects in which the Dative EPC differs from the benefactive construction and the judicantis construction, and thus according to which they can be distinguished.

First, when the Dative EPC is used, the speaker believes that the dative entity is affected by the event either beneficially or adversely. ${ }^{7}$ For example, in (3a) (Bule's cutting Damboowa's nails), the speaker believes that the possessor was beneficially affected by the event, whereas in (3b) (Bule's cutting Damboowa's sibling), the speaker believes that the possessor was adversely affected by the event. In (3c) (Bule's cutting Damboowa's tree), the beneficial or adversative interpretation is possible depending on the context. In any of these examples, the agent's performance of the action is independent of his/her intention to cause any effect on the possessor; the agent performs the action not necessarily with a belief that the result of the action affects the possessor. The subject's belief is expressed in the subtypes of the Dative EPC that have the other syntactic patterns as well.

On the other hand, in the benefactive construction, the subject's belief is not expressed. The subject normally performs the action with intentionality, and the

\footnotetext{
${ }^{7}$ This seems to apply even when the possessor in the Dative EPC is inanimate. Sentences like (4), (6), (8), and (10) report the state-change or state as the speaker perceives it, but also convey the speaker's belief that the state-change or state is beneficial or adversative to (the existence or function of) the dative entity.
} 


\section{Dative External Possessor Construction in Sidaama}

subject NP usually refers to an agent. What is expressed in this construction is the agent's intended performance of the action with a belief that the action is beneficial to the dative entity. For example, in (19), the agent ('she') performs the action of cutting her/that tree in the belief that the action would be beneficial to me/him. This belief is the agent's, and the event is described from the agent's viewpoint, though the judgment about whether or not the action is really beneficial to the dative entity is ultimately made by the dative entity. As in the English translations of (19), these sentences are neutral as to whether the dative entity wants the agent to perform the action.

In the judicantis construction, the subject's belief is usually not expressed, either; what is expressed in this construction is the dative entity's judgment. ${ }^{8}$ In (20a), the patient/theme entity's ('Damboowa's') state change (or resultative state) is depicted in the dative entity's ('her') judgment. Similarly, in (20b), the patient/theme entity's ('Damboowa's') state is described in the dative entity's ('her') judgment.

Another difference between the Dative EPC and the benefactive and judicantis constructions is the inferrability of a possessive relation between the dative entity and the patient/theme entity. In the Dative EPC, a possessive relation can be inferred between the two entities. On the other hand, in neither the benefactive nor judicantis constructions can a possessive relation be inferred between them.

An instance of one of the Sidaama dative constructions that has the structure (21a), (22a), or (22b) is interpreted as an instance of the Dative EPC when the patient/theme entity is expressed with a common noun without any dependent that is not accompanied by the possessive pronominal suffix referring to an entity other than the dative entity. On the other hand, in the benefactive and judicantis dative constructions, the patient/theme NP can be expressed with any type of nominal. Both in (19) and (20), where the patient/theme NP cannot be a possessum NP, Dative EPC interpretations are impossible.

A sentence with the structure (21a), (22a), or (22b), where the patient/theme entity is expressed by an inherently or obligatorily, as opposed to an optionally, possessed noun with neither any dependent nor the possessive pronominal suffix referring to an entity other than the dative entity, can be ambiguous between an EPC interpretation and a non-EPC interpretation, specifically a benefactive interpretation or a judicantis interpretation, though the Dative EPC interpretation is preferred whenever a possessive relation can be inferred. For example, other possible, though less likely, interpretations of $(3 \mathrm{c})$ and $(5 \mathrm{c})$ are 'Bule cut the tree for Damboowa' and 'The tree became tall in Damboowa's judgment', respectively.

\footnotetext{
${ }^{8}$ However, in the judicantis construction where the dative entity is inanimate (e.g., 'This table is tall for that chair.'), the dative entity's judgment is not present. An inanimate entity normally does not make a judgment, and the subject's judgment is expressed.
} 


\section{Kazuhiro Kawachi}

\section{Conclusion}

There are three findings of the present study. First, contrary to König \& Haspelmath's (1998; Haspelmath 1999) hypothesis, the Dative EPC exists in Sidaama. Second, the Sidaama dative marker is used for almost all the senses on Haspelmath's (1999) semantic map of a dative marker, where a dative marker is not supposed to occupy too much area. Third, the Sidaama EPC is related not only to the benefactive construction but also to the judicantis construction, and the Dative EPC differs from these two other dative construction in the subject's belief that is expressed and in a possessive relation inferred between the dative and patient/theme entities. A possible future study is an investigation of the uses of the datives in other Cushitic languages and their similarities with or differences from the dative in Sidaama.

\section{References}

Chappell, Hilary, and William McGregor. 1996. Prolegomena to a Theory of Inalienability. In Chappell, Hilary, and William McGregor. eds. The Grammar of Inalienability: a Typological Perspective on Body Part Terms and the PartWhole Relation, 3-30. Berlin: Mouton de Gruyter.

Haspelmath, Martin. 1999. External Possession in a European Areal Perspective. In Payne, Doris, and Immanuel Barshi. eds. External Possession, 109-135. Philadelphia: John Benjamins.

Kawachi, Kazuhiro. 2004. Middle voice and reflexive in Sidaama. In Adams, Nikki, Adam Cooper, Fey Parrill, and Thomas Wier. eds. CLS 40, Volume 2: Panels.

Kawachi, Kazuhiro. 2006a. External Possessor Constructions in Sidaama. In Bunting, Jacqueline, Sapna Desai, Robert Peachey, Christopher Straughn, and Zuzana Tomkova. eds. CLS 42, Volume 1: the Main Session. Chicago, IL: Chicago Linguistic Society.

Kawachi, Kazuhiro. 2006b. Feelings in Sidaama. In Reich, Peter, William Sullivan, and Arle Lommel. eds. LACUS Forum 33. Houston, TX: Linguistic Association of Canada and the United States.

Kawachi, Kazuhiro. 2007. A Grammar of Sidaama (Sidamo), a Cushitic Language of Ethiopia. PhD dissertation, University at Buffalo, SUNY.

König, Ekkehard, and Martin Haspelmath. 1998. Les Constructions à Possesseur Externe dans les Langues d'Europe. In Feuillet, Jack. ed. Actance et Valence dans les Langues de l'Europe, 525-606. Berlin: Mouton de Gruyter.

Payne, Doris L., and Immanuel Barshi. 1999. External Possession: What, Where, How, and Why. In Payne, Doris L., and Immanuel Barshi. eds. External Possession, 3-29. Philadelphia: John Benjamins.

Kazuhiro Kawachi

kazuhirokawachi@gmail.com,kazuhirokawachi@hotmail.com 